\title{
EXPERIENCE OF INGUINAL HERNIA REPAIR IN 230 PATIENTS BY LICHTENSTEIN TECHNIQUE
}

\author{
Mahesh Gupta1, Pawan Saini², Pooja Gupta3 ${ }^{3}$ Manoj Gupta ${ }^{4}$ \\ ${ }^{1}$ Associate Professor, Department of Surgery, Rama Medical College Hospital and Research Centre, Mandhana, Kanpur, Uttar Pradesh. \\ ${ }^{2}$ Senior Resident, Department of Surgery, MMIMSR, Mullana, Ambala. \\ ${ }^{3}$ Consultant, Department of Medicine, SGL Charitable Hospital, Jalandhar. \\ ${ }^{4}$ Consultant, Department of Surgery, SGL Charitable Hospital, Jalandhar.
}

ABSTRACT
BACKGROUND
The main aim of the surgeon is to lower the recurrence rate while dealing the defect in inguinal canal. Lichtenstein technique has
opened a new era in such repairs. In our study we have evaluated 230 patients who have undergone mesh repair in inguinal hernias
by Lichtenstein technique.

\section{MATERIAL AND METHODS}

The study was done prospectively from September 2013 to August 2015. Surgery related complications, operative time, hospital stay and return to routine activities were recorded. All the patients with age more than 15 years were included in this study; however patients with medical diseases like diabetes mellitus and chronic obstructive pulmonary disease were not included. Also patients with complications of hernia having features of obstruction or strangulation were also excluded from this study.

\section{RESULTS}

Out of 230 patients, 223 patients (96.95\%) were male and 07 patients (3.04\%) were female. Indirect inguinal hernia was present in 122 patients (53.04\%), direct inguinal hernia in $93(40.43 \%)$ and pantaloon hernia in 15 patients (6.5\%). The incidence of unilateral hernia was $75.21 \%$ whereas bilateral hernia was observed only in $24.78 \%$ patients. Postoperative seroma and haematoma was observed in 3 and 1 patient respectively which were drained successfully. None of our patients encountered postoperative neuralgia, wound infection or recurrence till date.

\section{CONCLUSION}

Lichtenstein technique of inguinal hernia repair in adults is still considered as the method of choice by many surgeons around the world in lieu of its simplicity in performing the procedure, minimum postoperative complications, early recovery with return to normal activities, less hospital stay and very low recurrence rate.

\section{KEYWORDS}

Lichtenstein technique, Inguinal Hernia Repair, Recurrence.

HOW TO CITE THIS ARTICLE: Gupta M, Saini P, Gupta P, et al. Experience of inguinal hernia repair in 230 patients by Lichtenstein technique. J Evolution Med Dent Sci 2016;5(2):109-111, DOI: 10.14260/jemds/2016/26

\section{INTRODUCTION}

Inguinal hernia is the abnormal protrusion of a part or whole of the viscus through the inguinal canal either via the deep inguinal ring (55\%) or directly through the posterior wall $(30 \%)$ of inguinal canal or both $(15 \%) \cdot{ }^{1}$ Repair of inguinal hernia is the most commonly performed general surgical procedure worldwide and it is done with a goal to prevent complications of hernia especially obstruction and later on strangulation; repair of the defect in a way to minimize the chance of recurrence and early return of the patient to normal activities. There are several methods of inguinal hernia repair mentioned in the literature after the introduction of Bassini in 1889 and all these methods mainly aim at tissue approximation. $^{2-6}$

Financial or Other, Competing Interest: None.

Submission 14-12-2015, Peer Review 15-12-2015,

Acceptance 31-12-2015, Published 05-01-2016.

Corresponding Author:

Dr. Mahesh Gupta,

Associate Professor

Rama Medical College Hospital and Research Centre,

Mandhana, Kanpur-209217,

Uttar Pradesh.

E-mail: gm982003@yahoo.co.in

DOI: $10.14260 /$ jemds/2016/26
However, due to increasing incidence of recurrence, these methods were replaced by tension free repair which reinforces the posterior wall of inguinal canal by a suitable material. Lichtenstein Hernia Institute introduced open technique of such tensionless repair by the use of mesh in1984andlater on laparoscopic mesh repair was performed in year 1991-1992.7-9 The recurrence rate of more than $15 \%$ has been reported in the literature in patients undergoing hernia surgery and the main aim of the surgeon is to lower the recurrence rate while dealing the defect in inguinal canal. Lichtenstein technique has opened a new era in such repairs. ${ }^{10}$ In our study we have evaluated 230 patients who have undergone mesh repair in inguinal hernias by Lichtenstein technique.

\section{MATERIALS AND METHODS}

Two hundred and thirty patients of inguinal hernia were admitted in surgical unit of Rama Medical College Hospital and Research Centre, Mandhana, Kanpur, UP, and all of them had undergone open hernia repair by Lichtenstein technique by the same surgeon. The study was done prospectively from September 2013 to August 2015.

Surgery related complications, operative time, hospital stay and return to routine activities were recorded. All the 
patients with age more than 15 years were included in this study, however patients with medical diseases like diabetes mellitus and chronic obstructive pulmonary disease were not included. Also patients with complications of hernia having features of obstruction or strangulation were also excluded from this study. Recurrent hernias, associated inguinoscrotal diseases like hydrocele, spermatocele were also excluded.

All these patients were given spinal anesthesia and opened with a groin incision above the inguinal ligament in the medial part. Skin, subcutaneous tissue and external oblique aponeurosis were incised in the same line and the spermatic cord along with the hernial sac was identified. In indirect hernias, sac was ligated near the deep inguinal ring after separating it from the spermatic cord whereas in case of direct inguinal hernias, sac was plicated. This was followed by the placement of appropriate sized polypropylene mesh in the posterior wall which was tied to the pubic tubercle, inguinal canal below , conjoint tendon above and around the spermatic cord at the deep inguinal ring using $2 / 0$ polypropylene suture. This was followed by closure of external oblique aponeurosis, subcutaneous fat and skin. The skin sutures were removed on 8th to 9 th postoperative day.

\section{RESULTS}

Out of 230 patients, 223 patients (96.95\%) were male and 07 patients (3.04\%) were female. Most of these patients were in the age group of 30 to 50 years. Indirect inguinal hernia was present in 122 patients (53.04\%), direct inguinal hernia in 93(40.43\%) and pantaloon hernia in 15 patients $(6.5 \%)$. The incidence of unilateral hernia was $75.21 \%$ whereas bilateral hernia was observed only in $24.78 \%$ patients. The average operating time in all these patients was 30 minutes in unilateral hernia and 50 minutes in bilateral cases. Mean hospital stay was 1 day with return to normal day to day activities in 2 days followed by complete recovery in 3 weeks.

There was minimal postoperative pain which was managed by simple analgesics. Postoperative seroma and haematoma was observed in 3 and 1 patient respectively which were drained successfully. Scrotal swelling was also observed in 4 cases which subsided of its own in 15 days. 9 patients had urinary retention in the postoperative period especially elderly patients with grade 1 prostatomegaly without any previous history of urinary retention. They were also successfully managed by simple catheterization for 2 to 3 days. None of our patients encountered postoperative neuralgia, wound infection or recurrence till date.

\section{DISCUSSION}

Introduction of the techniques for hernia repair ways back to more than 150 years and the problem of recurrence had been a serious concern for the operating team in all these techniques which include tissue approximation of the defects, use of autologous tisssues as well as other biomaterials. The use of polyethylene by Usher in year 1959 to repair the tissue defects lead to the introduction and interest in using prosthetic materials which was further reinforced by the reports of Stoppa (1975) and Lichtenstein (1984) suggesting many advantages of these prosthetic materials. ${ }^{10-14}$

Lichtenstein tension-free mesh repair has actually changed the scenario of treating the inguinal hernias due to its advantages like minimal postoperative pain, simplicity in performing the procedure under regional anesthesia and local anesthesia and above all a very low recurrence rate. ${ }^{10,15}$ These advantages have made it the procedure of choice in repairing inguinal hernias for many surgeons around the world.

The type of mesh to be used has also become a matter of concern as this foreign material should be inert, infection resistant and biocompatible. ${ }^{16,17}$ For this matter various types of polypropylene mesh are available and have the advantage of being monofilament, porous and non-absorbable and these features allow adequate collagen deposition, bacterial resistance and decrease in the incidence of recurrence. ${ }^{18,19}$ The incidence of recurrence further depends upon the technique used for placing the mesh and it should therefore be placed properly beneath the external oblique aponeurosis and above the posterior wall of inguinal canal with minimal folding or wrinkling of the mesh around the spermatic cord. Lichtenstein tension-free mesh repair is a safe, simple and effective in decreasing the recurrence rates of inguinal hernia and rates as low as $0-0.7 \%$ have been reported in the literature. ${ }^{1}$

\section{CONCLUSION}

Lichtenstein technique of inguinal hernia repair in adults is still considered as the method of choice by many surgeons around the world in lieu of its simplicity in performing the procedure, minimum postoperative complications, early recovery with return to normal activities, less hospital stay and very low recurrence rate, especially in hands of experienced surgeon and we strongly recommend its use in the repair of inguinal hernias and advise the residents to gain expertise in this procedure.

\section{REFERENCES}

1. Sakorafas GH, Halikias I, Nissotakis C, et al. Open tension free repair of inguinal hernias; the Lichtenstein technique. BMC surgery 2001;1:3.

2. Desarda MP. Physiological repair of inguinal hernia: a new technique (study of 860 patients). Hernia 2006;10:143-146.

3. Desarda MP. No-mesh inguinal hernia repair with continuous absorbable sutures: A dream or reality? (a study of 229 patients). Saudi journal of gastroenterology: official journal of the Saudi Gastroenterology Association 2008;14:122.

4. Gordon TL. Bassini's Operation for Inguinal Hernia. British medical journal 1945;2:181.

5. Manyilirah W, Kijjambu S, Upoki A, et al. Comparison of non-mesh (Desarda) and mesh (Lichtenstein) methods for inguinal hernia repair among black African patients: a short-term double-blind RCT. Hernia 2012;16:133-144.

6. Wennström I, Berggren P, Åkerud L, et al. Equal results with laparoscopic and shouldice repairs of primary inguinal hernia in men. Report from a prospective randomised study. Scandinavian Journal of Surgery 2004;93:34-36.

7. Blamey SL, Wale RJ. Laparoscopic repair of inguinal hernia. The Medical journal of Australia 1991;155:718.

8. Lichtenstein IL, Shulman AG. Ambulatory outpatient hernia surgery. Including a new concept, introducing tension-free repair. International surgery 1985;71:1-4.

9. Schultz LS, Graber JN, Pietrafitta J, et al. Early results with laparoscopic inguinal herniorrhaphy are promising. Clinical laser monthly 1990;8:103. 
10. Lichtenstein IL, Shulman AG, Amid PK, et al. The tensionfree hernioplasty. The American Journal of Surgery 1989;157:188-193.

11. Stoppa R, Petit J, Henry X. Unsutured Dacron prosthesis in groin hernias. International surgery 1975;60:411-412.

12. Usher FC. A new plastic prosthesis for repairing tissue defects of the chest and abdominal wall. The American Journal of Surgery 1959;97:629-633.

13. Usher FC, Fries JG, Ochsner JL, et al. Marlex mesh, a new plastic mesh for replacing tissue defects: II. Clinical studies. AMA archives of surgery 1959;78:138-145.

14. Wantz GE. Giant prosthetic reinforcement of the visceral sac. Surgery, gynecology \& obstetrics 1989;169:408-417.
15. Amid PK, Shulman AG, Lichtenstein IL. Open "tensionfree" repair of inguinal hernias: the Lichtenstein technique. Eur J Surg 1996;162:447-453.

16. Brown CN, Finch JG. Which mesh for hernia repair? Annals of the royal college of surgeons of England 2010;92:272-278.

17. Klosterhalfen $B$, Junge $K$, Klinge U. The light weight and large porous mesh concept for hernia repair. Expert review of medical devices 2005;2:103-117.

18. Amid PK, Lichtenstein IL, Shulman AG, et al. Biomaterials for "tension-free" hernioplasties and principles of their applications. Minerva chirurgica 1995;50:821-826.

19. Morris-Stiff GJ, Hughes LE. The outcomes of nonabsorbable mesh placed within the abdominal cavity: literature review and clinical experience. Journal of the American College of Surgeons 1998;186:352-367. 